\title{
¿Qué es un movimiento social? y su importancia en el estudio de la ciencia política
}

\author{
What is a social movement? And its importance \\ in the study of political science
}

\author{
José Gregorio Contreras H. \\ Doctor en Ciencias Políticas. \\ Profesor Asociado de la Universidad Central de Venezuela \\ ORCID 0000-0002-7470-6722 \\ Correo: josegregorio1968@gmil.com
}

\footnotetext{
Cómo citar este artículo:

Contreras, J. G. (2022). ¿Qué es un movimiento social? Y su importancia en el estudio de la ciencia política. Revista de la Facultad de Derecho y Ciencias Políticas, 52(136), pp. 68-100. doi: https://doi. org/10.18566/rfdcp.v52n136.a04
}

Recibido: 24 de agosto de 2020

Aprobado: 17 de marzo de 2021 


\section{Resumen}

Este artículo es producto de la revisión bibliográfica y de reflexiones surgidas acerca de esta con nuestros alumnos en la Cátedra de Historia de las Ideas y Movimientos Sociales Contemporáneos, dictada en la Escuela de Estudios Políticos y Administrativos de la Universidad Central de Venezuela: al comprobar en las lecturas que no hay una precisión conceptual que permita definir qué realmente se entiende por movimiento social, ante las diferentes interpretaciones que del concepto se observan, así como del exagerado uso de la idea para calificar las diferentes manifestaciones sociales que han tenido lugar en Venezuela, España y otras partes del mundo en estos últimos tiempos, lo que genera confusión para identificar claramente qué es un "movimiento social".

El trasfondo que anima este artículo es proponer una definición más precisa del concepto que permita clarificarlo mediante la identificación de cada uno de los elementos que forman parte de su contenido. Para ello se hace un análisis de las diversas conceptualizaciones en su evolución histórica, desde que fue empleado por Lorenz Von Stein hasta nuestros días, resaltando la importancia de esta precisión conceptual para el avance en la comprensión de un campo de estudio tan fundamental para la ciencia política. Su construcción busca diferenciar el movimiento social de cualquier otra forma de acción colectiva, específicamente del movimiento político.

\section{Palabras clave}

Movimiento social; movimiento político; politización; partidización; fenómeno políticamente condicionante; fenómeno políticamente condicionado.

\section{Abstract}

This article is the product of the bibliographic review and reflections that emerged about it with our students in the History of Contemporary Social Ideas and Movements class, taught at the School of Political and Administrative Studies of the Central University of Venezuela; when realizing in the readings that there is no conceptual precision that allows defining what is really understood by social movement, given the different interpretations of the concept that are observed, as well as the exaggerated use of the idea to qualify the different social manifestations that have taken place in Venezuela, Spain, and other parts of the world in recent times, generating confusion to clearly identify what a "social movement" is.

The background that inspires this article is to propose a more precise definition of the concept that will allow to clarify it, by identifying each of the elements that are part of its content.

For this, an approach is made of the various conceptualizations in their historical evolution, from when it was firstly used by Lorenz von Stein until today, highlighting the importance of 
this conceptual precision of the progress in understanding a field of study that is so important for Political Science.

Its development seeks to differentiate the social movement from any other form of collective action, specifically from the political movement.

\section{Keywords}

Social movement; political movement; politicization; partisanship; politically conditioning phenomenon; politically conditioned phenomenon.

\section{Introducción}

El presente artículo responde a un conjunto de interrogantes y reflexiones que surgen al apreciar las diversas conceptualizaciones que se han dado de movimientos sociales, expresadas en la bibliografía especializada disponible, desde que lo definió Lorenz Von Stein, hasta nuestros días, incorporando en su contenido diversidad de elementos que impiden la comprensión de estas categorías de análisis y, en consecuencia, diferenciarlo de otras formas de acción colectiva ${ }^{1}$.

Lo primero en destacar es que el concepto de movimiento social tiene un carácter polisémico, y que las diferentes interpretaciones dadas por múltiples autores $^{2}$ sobre el tema dan pie a la falta de una definición precisa de este concepto, a su vez, impiden distinguir con meridiana claridad los movimientos sociales de otros fenómenos colectivos, entorpeciendo el desarrollo de un campo cada vez más notable en el estudio de la ciencia política.

Al partir de esta preocupación académica a la luz de la teoría política y, entender que los conceptos son fundamentales para explicar y también acumular realidades, como muy bien lo dice Koselleck (2012), cuando plantea:

Toda vida humana está constituida por experiencias, bien sean estas nuevas y sorprendentes o, por el contrario, de naturaleza repetitiva. Se necesitan conceptos para poder tener o acumular experiencias e incorporarlos

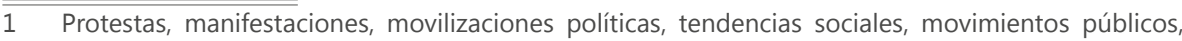
entre otros.

2 Lorenz Von Stein, Alain Touraine, Enrique Laraña, Benjamín Tejerina, Sidney G. Tarrow, Killian L.M, Turner R.H, Charles Tilly, Pedro Ibarra, Luis Salamanca, entre otros.
} 
vitalmente. Son necesarios para fijar experiencias que se diluyen, para saber qué sucedió y para conservar el pasado en nuestro lenguaje. Los conceptos son por tantos necesarios para integrar las experiencias pasadas tanto en nuestro lenguaje como en nuestro comportamiento. (Koselleck, 2012, p. 29).

En nuestras clases surgió la preocupación por definir un concepto de movimiento social que permita la clarificación y entendimiento de este fenómeno, creando un marco interpretativo de mayor comprensión en sus categorías de análisis y, así, contribuir a un mejor estudio y análisis de esta forma de acción colectiva.

Al asumir que la historia del conocimiento y de la búsqueda de la verdad científica puede entenderse como la historia de grandes debates y discusiones teóricas, (cuestión que se hace recurrente en cada época y cada generación), se ha de entender también que es, precisamente, en la continuidad (ad infinitum) de este proceso epistémico donde se sustenta la posibilidad de que los estudiosos elaboren y reelaboren interpretaciones que permitan, en el orden gnoseológico, comprender, valorar, representar y explicar la realidad con mayor grado de aproximación en la concordancia entre los fenómenos estudiados y lo que de estos se aprende y predica.

En este caso la discusión se propone realizar algunos aportes al concepto de movimiento social, los cuales se estiman necesarios en orden a la disminución o eliminación total de la ambigüedad observada en las interpretaciones de diversas acciones sociales como movimiento social, y en procura de lograr su necesaria especificidad teórica: siguiendo en la línea de las concepciones que lo ubican afiliado a la lógica de la acción colectiva. Para esto se identifican los elementos que, en el orden teórico, permiten delimitarlo, clarificarlo y diferenciarlo de las múltiples formas en la que esta se expresa, a objeto de que pueda ser usado adecuadamente por la ciencia política para estudiar, en forma discriminada o específica y con consideración de sus diversas implicaciones, los distintos fenómenos que se producen en los ámbitos sociales y políticos, y además procurando que se entienda su relevancia como una forma de participación política no institucionalizada políticamente y como la fuerza moral de cambio de mayor distinción de la sociedad actual, con lo cual se coadyuvará en el avance de un campo fundamental de estudio para la politología.

Para tal propósito; i), se expone la evolución del concepto de acuerdo con la interpretación de varios autores con el fin de mostrar los contrastes y alcances; ii), la reinterpretación del concepto de movimiento social en el 
marco del nuevo paradigma de hoy, donde se entiende que el productor de movimiento social no es la cuestión social sino la cultural con el fin de mostrar rupturas y continuidades; iii, los movimientos sociales y la inclusión del otro, con el objeto de reinterpretar el concepto en el contexto del debate actual dentro de la concepción de los tipos de democracia normativa planteada por Habermas (2004); iv, el movimiento social y su reprecución para la participación, con el fin de aclarar el tema de la inclusión del otro al indicar que los límites de la comunidad están abiertos para todos, y precisamente también para aquellos que son extraños para los otros y quieren continuar siendo extraños, al poner en claro el concepto de movimiento social cuando se hace el análisis de eventos como los vividos en Venezuela el 2007 y en España el 2015 , permitiendo apreciar con mayor claridad al objeto central de este artículo, el cual es precisar un concepto de movimiento social y poner en evidencia su importancia para la ciencia política; y v), las consideraciones finales.

\section{Evolución del concepto}

Aunque los alborotos, revueltas, manifestaciones, protestas y otras formas de acción colectiva se registraron en la Edad Media y en épocas más remotas, como por ejemplo los varios hechos narrados en la Biblia (vale decir que el uso del término "movimiento" ha sido empleado en épocas anteriores y con diversos significados), es a partir de la modernidad cuando las acciones colectivas se enmarcan en acciones donde la sociedad podría ser organizada conscientemente de acuerdo con proyectos propios, y no como en la Edad Media donde las diferentes formas de protesta contra la autoridad apuntaban al restablecimiento de un orden tradicional o divino que se veía como vulnerado.

Tal como lo sostiene Haydde Farías (1981), va a ser Lorenz Von Stein ${ }^{3}$, el primero que intentó elaborar un concepto “científico” y desplegarlo en una teoría social, en la que veía a la revolución francesa:

[...] no como un cambio en la estructura gubernamental, sino que destaca y pone en primer plano la estructura de la sociedad, el antagonismo entre Estado y Sociedad y los intereses y conflicto de clases como determinantes en el cambio político. Luego desarrolló el concepto de proletariado, aplicándolo a las nacientes clases obreras industriales de las ciudades de

3 Lorenz Von Stein, fue el primero en intentar elaborar un concepto "científico" de movimiento social y desplegarlo en una teoría social, en su libro: Historia del movimiento social en Francia, 1789-1850. 
Europa Occidental y vio en los conflictos y disturbios protagonizados por esa clase actuando como tal, cohesionadamente, el desarrollo más crucial de su época. De allí que calificara a los esfuerzos de la clase obrera hacia la organización y por la obtención del poder político y económico como 'el' movimiento social. (Von Stein citado en Farías M, 1981, p. 97).

En este primer intento de conceptualización de movimiento social se observa que el autor lo contextualiza dentro de los esfuerzos que realiza la nueva clase obrera industrial por lograr la organización y los cambios políticos. Von Stein (1850) sitúa su análisis de los conflictos y el movimiento, especificando que el verdadero significado político del socialismo y el comunismo no radica tanto en su valor como forma de pensamiento social, en cuanto el hecho de que servían de expresión y cauce a los esfuerzos del proletariado industrial para implantar un nuevo orden social.

El uso de este concepto operó como un marco rector en las escuelas alemanas y austríacas de historiadores del socialismo durante todo el siglo XIX. El "movimiento social” es concebido en esta época como expresión de la clase obrera. El análisis de los vínculos entre movimiento obrero y el término movimiento social, va a ser la línea de pensamiento que marca esta época, es el caso de Werner Sombart (citado en Farías, 1981), representante de dicha escuela (Socialism and the social Movement), quien define el movimiento como: "la concepción de todos los intentos del proletariado por lograr su emancipación” (Sombart citado en Farías, 1981, p.97).

Estos dos autores identifican y enmarcan el concepto de movimiento social con todo lo que tenga que ver con el movimiento obrero, (de allí que en ese momento histórico se entendía por movimiento social al movimiento obrero), este era considerado como el verdadero movimiento social, sin duda que esta percepción ha cambiado actualmente y es lo que permite hablar de la evolución del concepto. Tal interpretación del concepto de acuerdo con la realidad del momento y en consecuencia el carácter polisémico del mismo, es lo que a su vez ha dado lugar a una confusión del término.

Esta evolución del concepto es lo que denota que siempre ha habido un intento de definición de este y así darle explicación a los fenómenos del momento en el contexto histórico específico, lo demuestra Rudolf Haberle (citado en Farías, 1981, p. 98-101), cuando más allá de la mitad del siglo XX expande el concepto a fenómenos tales como movimientos campesinos y granjeros, fascismo y nazismo, movimientos de independencia nacional, entre otros. Para 
este autor la característica fundamental del movimiento social es su aspiración para producir cambios radicales en el orden socioeconómico y político, sobre todo en las relaciones de propiedad y poder. Para él los movimientos sociales $^{4}$ no son grupos organizados, y aunque pueden tener ciertas normas de organización, van más allá de ella. No existe una organización per se para el movimiento social. Reconoce que los movimientos sociales requieren de la existencia de conciencia, identidad y solidaridad entre sus miembros.

Paul Wilkinson (citado por Farías, 1986, p. 101) critica el concepto de Haberle por considerar que lo encasilla en un conflicto de grupos sociales por imponer un proyecto social, y plantea que este concepto debe ser más operativo y de aplicación interdisciplinaria, por lo que propone como definición que: "un movimiento social es un intento colectivo deliberado por promover cambios en cualquier dirección y por cualquier medio, sin excluir la violencia, ilegalidad, revolución o aislamiento en una comunidad utópica.” (Wilkinson citado por Farías, 1986, p. 101). Este concepto no permite interpretar lo que actualmente define a un movimiento social, ya que este debe ser entendido como una acción colectiva que busca lograr cambios a través del reconocimiento del derecho de los otros, sin necesidad de alcanzar el poder y sin generar violencia, sino que, por el contrario, lograr consensos a través del reconocimiento del derecho de los que luchan, situación que se produce por la presión generada de las acciones colectivas del movimiento.

En este orden cronológico de intentos de definición se ubica por último a Alain Touraine (2005), para cerrar esta primera parte de lo que ha sido la interpretación de los movimientos sociales dentro de lo que llamaría Claus Offe (1988) la lógica del viejo paradigma, y dar paso al eje central de este análisis, el cual es determinar un nuevo concepto que permita diferenciarlo de las otras diversas manifestaciones sociales de acciones colectivas que experimenta la sociedad actualmente donde existe la tendencia a ser confundidas.

Entiende Touraine, en este momento histórico, más allá de la mitad del siglo $\mathrm{XX}$, que movimiento social: "es la acción conflictual de agentes de clases sociales que luchan por el control del sistema de acción histórica” (Touraine citado en Farías, 1986, p.103). Sin duda un concepto de corte marxista que

$4 \quad$ Rudolf Haberle en su libro Social Movemennts: An introductión to political Sociology, 1951. 
actualmente no es útil para entender los nuevos movimientos sociales $^{5}$, y que el mismo Touraine (2005) supera en su libro "Un nuevo paradigma para entender el mundo de hoy", cuando nos dice:

El consecuente derrumbamiento de las categorías sociales de análisis y de acción no es un acontecimiento sin precedentes. En los comienzos de nuestra modernización, pensábamos los hechos sociales en términos políticos -orden, desorden, soberanía, autoridad, nación, revolución-, y no fue sino después de la revolución industrial cuando sustituimos las categorías políticas por categorías económicas y sociales (clases, beneficio, competencia, inversión, negociaciones colectivas). Los cambios actuales son tan profundos que nos llevan a afirmar que un nuevo paradigma está sustituyendo al paradigma social, del mismo modo que este ocupó el lugar del paradigma político. (Touraine, 2005, p. 257).

Ya aquí se observa un cambio radical en un autor que solo consideraba que era movimiento social aquellos que lograban un cambio total, en su entender solo las revoluciones.

\section{Reinterpretación del concepto de movimiento social en el marco del nuevo paradigma}

La noción de movimiento social ha recibido diferentes conceptualizaciones desde la revolución industrial hasta nuestros días. Por tal razón el objeto de este artículo es aproximarse a una conceptualización que permita interpretar los cambios que experimenta la sociedad actual: siguiendo a Weber (1984), lo que buscamos es la elaboración de un concepto funcional en términos de su relación al "todo" que, de acuerdo con su utilidad e indispensabilidad lo podamos poner correctamente en práctica en la interpretación de la realidad fuera de toda duda. Lograr un concepto idóneo es fundamental para entender el desenvolvimiento de la época que vivimos donde, parafraseando a Touraine (2005), ya no es el paradigma social el productor de movimientos sociales, sino

5 Los nuevos movimientos sociales no pueden ser interpretados actualmente con la visión marxista de lucha de clases, como lo dice Melucci (1986) "El marxismo clásico no va mucho más allá de una connotación económica (no política ni sociológica) de una clase explotada, productora de 'plusvalía' como potencial agente colectivo de la revolución socialista. Ni va mucho más allá de la indicación de la 'dictadura del proletariado' como forma política del poder revolucionario: un poder destinado, por otra parte, a agotarse rápidamente, gracias a la prevista 'extinción del Estado' (P.68). En los movimientos sociales de hoy participan todas las clases sociales, y como dice Touriane (2005), ya no es el paradigma social el productor de movimiento social sino el paradigma cultural. 
el paradigma cultural; ya no es la clase social el motor de los cambios, sino el "sujeto consciente" ${ }^{6}$ el productor del cambio, activado en movimiento social

Se inicia esta disertación con Alberto Melucci (1986), quien, inspirado con su doctorado en París, en 1970, bajo la dirección de Alain Touraine en la École des Haute Études en Sciences Socilaes, por el énfasis que este ponía a la autonomía de la acción social, va a definir al movimiento social dentro de la lógica de las acciones e identidades colectivas. Sostiene que el movimiento social, es una acción colectiva, en estricto sentido, que va a estar determinada por un sistema de relaciones sociales que liga e identifica a aquellos que participan en él y además por la presencia de un conflicto. Y que la identidad colectiva es el proceso previo que da lugar a la construcción de definiciones compartidas de la situación social, lo que permite que los individuos involucrados en dicho proceso puedan evaluar la situación y unirse a la acción colectiva, siendo esta dinámica a nuestro parecer muy significativa para dar lugar al surgimiento del movimiento social como proceso.

Hasta este punto se está de acuerdo con el autor, sin embargo, no es una opinión compartida el decir que los movimientos sociales pueden ser distinguidos en movimientos reivindicativos, movimientos políticos, movimientos de clases. Para Melucci (1986), el movimiento reivindicativo se sitúa al nivel de la organización social y lucha contra el poder que garantiza las normas y roles; un movimiento de este tipo tiende a una redistribución de los recursos y a una reestructuración de los roles. El movimiento político actúa para transformar los canales de la participación política o para desplazar las relaciones de fuerza en los procesos decisionales. Su acción tiende a romper las reglas del juego y los límites institucionalizados del sistema impulsando la participación más allá de los límites previstos. El movimiento de clase es una acción colectiva dirigida contra un adversario para la apropiación, el control y la orientación de los medios de la producción social.

Esta distinción no es compartida, porque precisamente unas de las hipótesis que se sostiene en este análisis para definir ¿Qué es un movimiento social?, es su diferencia con otros tipos de acciones colectivas, por lo tanto, el movimiento social no "pueden ser distinguidos en", sino que "pueden ser

6 Se entiende por "Sujeto Consciente", tal como lo define Touraine (2005), aquel sujeto que no únicamente dice yo, sino aquel que tiene conciencia de su derecho a decir yo. Es un sujeto que impulsado o no por un movimiento social, se manifiesta en la conciencia del actor. No se podría hablar más de adhesión inconsciente a un movimiento social como no se puede hablar de creencias religiosas inconscientes. (Cfr. Touraine, 2005, p. 124-125). 
distinguidos de”, es decir, un movimiento reivindicativo, un movimiento político, un movimiento de clase no es un movimiento social, pueden ser movimientos con gran apoyo social, pero no son movimientos sociales, porque este va mucho más allá de estas acciones colectivas, pues en las discusiones dadas en las clases, se llegó a concluir que en el movimiento social la acción colectiva persigue metas para promover, impedir o reproducir un cambio social básico, tiene cierta continuidad que genera una identidad después de un proceso cognitivo de testeo de los objetivos que persiguen, que además de sus proponentes, en algunos casos son apoyados por personas que no son directamente beneficiados de las reivindicaciones que puedan alcanzar; o porque las acciones de sus voceros están dirigidas al cambio y no buscan alcanzar el poder, sino producir un cambio en él, lo que genera una fuerza moral de convocatoria que no logra otro movimiento de acción colectiva, ya que participan actores que no están directamente vinculados con los objetivos ni forman parte del grupo que los impulsa o porque logran una participación consensuada por todos los sectores de la sociedad por no estar partidizados.

Las anteriores características definen en la actualidad al concepto de movimiento social; siendo así, no puede ser considerado el movimiento: reivindicativo, político y de clase que distingue Melucci como movimiento social, ni mucho menos los otros tipos de acción colectiva.

El movimiento social no es producto de una consecuencia natural de procesos sociales, sino de las preferencias de los individuos por las necesidades y transformaciones de cambio de la sociedad. Por tal razón, el movimiento necesita de un proceso de racionalización del cambio para generar la identidad colectiva, que radica en un testeo de los elementos cognitivos e intencionales en los que se sustenta su orientación hacia el cambio, y a través de este proceso de articulación de las preferencias lograr la acción colectiva, por esta razón se considera a los movimientos sociales la forma de participación política no institucionalizada políticamente más trascendental, porque evita partidizarse, ya que requiere del mayor consenso de la sociedad para alcanzar el cambio social propuesto, constituyendo este el elemento distintivo de los movimientos sociales, cuyo propósito es el logro del mayor apoyo de la sociedad para impulsar el cambio.

Lo anterior es contrario al movimiento político, donde las decisiones están políticamente condicionadas y las discusiones del asunto en cuestión giran en torno a la posesión, intereses, la distribución y el cambio de poder como condición última para la solución al problema en discusión. En el movimiento 
político se genera una pugna por el ejercicio o por la influencia en el ejercicio del poder; distinto al movimiento social que no tiene una naturaleza estrictamente política, aunque busca influenciar en el ejercicio del poder para los cambios que se propone, su intención no es alcanzar el poder ni mayormente la necesidad de su reemplazo para lograr los cambios propuestos, no es condición sine qua non la sustitución del poder; aunque pueda darse el caso. La politización que genera el movimiento social es con el fin de condicionar a la política para el cambio y no lo hace en el marco de una confrontación de grupos de fuerzas con visiones distintas, sino en el marco de confluencias de fuerzas con la aspiración de lograr el mayor consenso para impulsar el cambio evitando la pugna grupal.

En esta línea de pensamiento también se ubica Charles Tilly (2009), cuando en su libro Los movimientos Sociales. 1768 - 2008, nos dice:

A pesar de las incesantes innovaciones y de las mínimas variaciones entre un contexto político y otro, los elementos que conforman el movimiento social evolucionaron y se propagaron como un todo interconectado. En este sentido, el movimiento social tiene su propia historia, diferente a la historia de otras formas políticas, como las campañas electorales, las celebraciones patrióticas, las exhibiciones de poderío militar, la toma de posesión de funcionarios públicos o el luto colectivo. Así, cuando este libro habla de movimientos sociales, no alude a todas las acciones populares, a todas las acciones de la gente en nombre de una causa, a todas las personas y organizaciones que respaldan esas mismas causas o a los actores heroicos que han destacado en la historia, sino a un conjunto histórico, concreto, interconectado y cambiante de interacciones y prácticas políticas a la combinación única de campañas, repertorios y demostraciones de WUNC"7. (Tilly, 2009, p. 29).

En su obra queda claro, que los analistas y los activistas a menudo emplean la expresión "movimiento social” de un modo más vago para incluir bajo ese paraguas cualquier actividad de protesta o, cuando menos, todas las protestas relevantes con las que están de acuerdo. Igualmente nos señala que:

Los analistas a menudo tratan "al movimiento" como un actor unitario, ensombreciendo así tanto (a) las disputas y los reajustes que constantemente se dan en el seno de los movimientos sociales como (b) la interacción entre los activistas, los votantes, los objetivos, las autoridades, los aliados, los

7 Las demostraciones de WUNC, traduce valor, unidad, número y compromiso. 
rivales, los enemigos y el público que conforman la textura cambiante de los movimientos sociales. (Tilly, 2009, p. 27-28).

Tilly (2009) es pesimista con respecto al futuro de los movimientos sociales en cuanto a sus cuatro premisas fundamentales: internacionalización, declive democrático, profesionalización y triunfo, y señala lo siguiente en cada una de ellas: en cuanto a la internacionalización nos dice que muchos observadores y activistas del siglo XXI asumen que la internacionalización ya está dejando huella, y que seguirá haciéndolo hasta que llegue el día en el que la mayoría de movimientos sociales actuarán a escala internacional 0 incluso global. Declive de la democracia, ¿Qué sucedería, sin embargo, si el declive de la democracia se debiera a causas ajenas a las esferas del movimiento social, como el debilitamiento de las barreras entre las desigualdades explícitas y la política pública 0 a la segregación de las redes de confianza ya existentes o nuevas con respecto a la política pública? Profesionalización, conduce a la institucionalización, y, por tanto, al descenso en términos de innovación en los movimientos sociales. Los populistas más contumaces a menudo se muestran preocupados porque los activistas del movimiento social, procedente en su mayoría de sectores de la población prósperos, instruidos y bien relacionados, acaben traicionando los intereses de la gente verdaderamente desfavorecida, establezcan relaciones de conveniencia con las autoridades, recurran más y más al apoyo de los ricos y de los poderosos o se conviertan en burócratas del movimiento social, más interesados en promover sus propias organizaciones y carreras que el bienestar de sus supuestos representados. Triunfo, ¿Qué hay de la expansión masiva de los movimientos sociales a todos los niveles, desde lo local hasta lo global? Una posibilidad tan sorprendente como esta precisaría de la democratización de las muchas regiones del planeta que viven bajo regímenes autoritarios o gobernadas por señores de la guerra o tiranías del tres al cuarto.

Aunque Tilly (2009) en sus planteamientos es pesimista al afirmar que solo el movimiento social crecerá si hay democracia, se sostiene aquí lo contrario al rescatar parte de su propio planteamiento, cuando expresa: "Son un canal fundamental para grupos, categorías y cuestiones que, hoy, no tienen presencia en la rutina política de un régimen y que no pueden alcanzar, por lo tanto, un lugar visible en la política" (Tilly,2009, p.303); y plantear que el movimiento social trasciende de la visión político-partidista y convoca a la acción colectiva para impulsar el cambio, porque busca que este sea asumido en las relaciones de poder sin pretender alcanzar el poder, y así impulsar las acciones para dicho cambio. Por lo tanto, aunque la democracia es fundamental para que el movimiento social se desarrolle, no es condición sine qua non para que 
surja y se consolide; tenemos como ejemplo las diversas manifestaciones ocurridas en Venezuela el 2007 como consecuencia de negársele la renovación de la licencia de trasmisión del canal de televisión RCTV y las manifestaciones contra la propuesta de reforma constitucional planteada por Hugo Chávez que buscaba conformar en el país un Estado socialista, todas ellas lideradas por el movimiento estudiantil, así como las ocurridas el 2014, 2016 y 2017 que buscaban la salida de Maduro del poder, las mismas se dieron a pesar de tener un gobierno altamente represivo que criminaliza la participación política, como se puede comprobar con la cantidad de jóvenes presos por protestar y las acusaciones contra líderes emblemáticos de la oposición como María Corina Machado, Antonio Ledezma y en el caso de Leopoldo López la privación de su libertad, por liderar un movimiento llamado "La Salida”, eso no ha sido excusa para que la gente se manifieste a través de grandes protestas; de la misma manera pueden surgir movimientos sociales, tal es el caso del movimiento social surgido el $2007^{8}$ en Venezuela, liderado por los estudiantes.

Estos planteamientos de Tilly (2009) se unen a la preocupación por definir un concepto de movimiento social que parta de la identificación de sus elementos para evitar confusiones como por ejemplo las que comete el actual gobierno venezolano cuando hace uso del concepto en sus diversas alocuciones públicas, para decir que sus "movimientos sociales” promueven el socialismo, lo que en términos científicos debe considerarse como una inaceptable ideologización de la sociedad, carente de toda sustentación teórica habida cuenta de que los movimientos sociales no son promovidos por gobiernos o estados, ni mucho menos para imponer ideas que vayan en contra de los derechos de los demás, por el contrario, su relación con el Estado y los gobiernos es conflictiva, y mucho más con las acciones que atenten contra la libertad.

Con toda esta disertación lo que se busca es desarrollar un concepto que permita ir más allá de las generalizaciones empíricas y distinguirlo de otras acciones colectivas que no lo son, pues el movimiento social se caracteriza por impulsar cambios que no van en desmedro ni en contra de los derechos de los demás, no sirve a intereses personales o partidista, luchan por un objetivo de

$\overline{8}$ El movimiento estudiantil 2007: surge por el cierre de Radio Caracas Televisión (RCTV), al negársele la renovación de la licencia de trasmisión, siendo la estación de televisión privada más antigua de Venezuela, y se consolida al aumentar sus manifestaciones contra la propuesta de reforma constitucional planteada por Hugo Chávez, ese mismo año, que buscaba conformar en el país un Estado socialista, el movimiento estuvo conformado por líderes estudiantiles de universidades públicas y privadas de toda Venezuela, por su compromiso a favor de la democracia y los derechos civiles básicos. Se declaraban explícitamente no-partidistas y únicamente buscaban promover la discusión y el cambio social. 
carácter deliberado y propositivo, esto es lo que le permite alcanzar la fuerza para impulsar el cambio propuesto.

Sí coinciden los autores, amplia y mayoritariamente, en torno a la idea que los movimientos sociales son acciones colectivas ${ }^{9}$ donde los involucrados comparten:

- Relaciones conflictivas con actores claramente identificados. Se tiene claro quién es el oponente, que aunque el conflicto surge en la sociedad por las diversas relaciones de intereses que se dan en ella, siempre el conflicto será con el Estado y el gobierno por ser estos los articuladores de los intereses de la sociedad y donde tienen que darse las transformaciones normativas e institucionales para el cambio que buscan.

- Se vinculan a través de diferentes formas de participación y organización.

- Comparten identidades colectivas claramente diferenciadas, solo los une el objetivo de lucha, lo que logra la identidad colectiva y la acción colectiva.

Por qué entonces, no unir criterios que permitan llegar a un acuerdo de universal aceptación acerca del concepto, y así evitar equívocos, si está claro que existe una diferencia de lo que es un movimiento social de un movimiento político, de una tendencia social, de un movimiento de opinión pública, de una explosión social, de una protesta, de un motín o cualquier otra acción colectiva.

En esta dirección apuntan autores como Della Porta y Diani cuando dicen en su libro Los Movimientos Sociales que:

Podemos identificar una dinámica de movimiento social cuando episodios individuales de acción colectiva se perciben como parte de una acción más duradera y no tanto como un acontecimiento aislado, y cuando los individuos implicados en ellos se sienten vinculados por lazos de solidaridad y se perciben como integrantes de una comunión ideal al lado de quienes protagonizan otras movilizaciones análogas. (Della Porta y Diani, 2011, p. 46).

9 Se entiende por acción colectiva, al proceso mediante en el cual los individuos asignan significado a sus propias experiencias y su cambio en el tiempo. Es a través de estas que se genera la identidad colectiva del movimiento, se refuerzan los sentimientos o debilitan. Este proceso da lugar a vínculos o conexiones que conllevan a sentimientos de solidaridad cuando logran identificarse con el movimiento, que permiten relaciones entre personas que normalmente no están vinculados por contactos personales directos, pero que comparten aspiraciones y valores. (Cfr. Donatella Della Porta y Mario Diani, 2011, p. 125-151) 
Si además de lo señalado por estos autores, se sigue el planteamiento de Max Weber (1984) de lo que es la acción social cuando dice:

En sí misma la acción no está relacionada con la conducta de otra persona, sino más bien surge a través de la observación que hace que el agente descubra ciertas posibilidades objetivas: hacia ella se orienta su acción. Su acción es causada por la otra persona, pero no extrae de ella su significado. (Weber, 1984, p.41).

Queda claro entonces, que el movimiento social surge del significado que los individuos le atribuyen recíprocamente a los objetivos e ideas de este, es decir, de la relación mínima entre la acción de cada persona y los demás. Es este comportamiento lo que permite alcanzar la acción colectiva que da lugar después de que se ha generado una identidad colectiva. El movimiento social no es producto de una manipulación, sino por el contrario, una acción consciente que se produce una vez que el individuo ha logrado una subjetivación ${ }^{10}$ del conflicto que da lugar a este, en otras palabras, el sujeto se activa como agente de movimiento social.

De acuerdo con Hunt, Benford y Snow (2001), este proceso de subjetivación se da a través de los marcos de referencias de la acción colectiva, que a su vez permiten actuar para la atribución y articulación de significados del movimiento social, es decir, son las interpretaciones que hacen los actores que se involucran en él las que permiten la identificación con este e integración al mismo, compartiendo de esta manera los supuestos que dan lugar a la movilización.

En definitiva, aquí se exponen a grandes rasgos las líneas de un debate que es tema de preocupación de varios estudiosos de la materia, como es el caso de Enrique Laraña, quien en su libro "La Construcción de los Movimientos Sociales”, manifiesta que: "La falta de precisión del concepto está relacionada con el pluralismo teórico que caracteriza a este campo de estudio con la existencia de distintos enfoques que parten de una concepción diferente de su objeto”. (Laraña, 1999, p.68).

10 Se entiende por subjetivación el proceso de construcción por el individuo o el grupo de sí mismos como sujeto, es decir, se es sujeto en tanto y en cuanto se reconozca los derechos humanos del otro como me reconozco a mí mismo como ser humano, como me reconozco obligaciones respecto de a mí mismo. En definitiva la subjetivación es un proceso de racionalización, tal como lo expresa en Touraine cuando dice que: "Ningún individuo, ningún grupo es íntegramente un sujeto. Es siempre más justo decir: "Hay sujeto en tal conducta o en tal individuo»". La conciencia del sujeto, que se produce con la subjetivación, es lo que permite la identidad colectiva, necesaria para producir la acción colectiva que da lugar al movimiento social. (Touraine, 2005, p. 129-179). 
En un intento de contribuir al debate, después de analizar el concepto propuesto por varios autores y estudiosos del tema de los movimientos sociales y tratando de hacer más comprensivo el concepto, Laraña (1999) nos deja una definición de movimiento social que:

[...]refiere a una forma de acción colectiva 1) que apela a la solidaridad para promover o impedir cambios sociales; 2) cuya existencia es en sí misma una forma de percibir la realidad, ya que vuelve controvertido un aspecto de ésta que antes era aceptado como normativo: 3) que implica una ruptura de los límites del sistema de normas y relaciones sociales en el que se desarrolla su acción; 4) que tiene capacidad para producir nuevas normas y legitimaciones en la sociedad” (Laraña, 1999, p. 126-127).

La necesidad en definir un concepto de movimiento social, obedece a que se consideran fenómenos de fundamental reputación en estos tiempos donde los partidos políticos han perdido credibilidad, donde la radicalización de las posturas ideológicas no permiten alcanzar acuerdos para lograr cambios en las sociedades que conduzcan a impulsar sus equilibrios y una mejor convivencia a través de un proceso tan inclusivo y de amplia participación como los son los movimientos sociales, de allí que es pertinente su clara definición y diferenciación de otros fenómenos colectivos para evitar tergiversarlos y perder una herramienta que se considera fundamental como nueva forma de participación política no institucionalizada políticamente, sin ser partidizada e ideologizada, con una amplia capacidad de convocatoria, venciendo así la resistencia y, como lo dice Laraña, de forma legítima.

\section{Los movimientos sociales y la inclusión del otro}

Los movimientos sociales, en una concepción moderna del término, surgen como una respuesta a los procesos de democratización y cambios que experimentan las sociedades contemporáneas, ya que ellos tienen la capacidad de mantener desafíos frente a oponentes poderosos. A esta conclusión se llega conducido por la integración crítica de un conjunto de lecturas especializadas en el tema. La lectura de Sidney Tarrow (2012), es una de ellas, quien en su libro: "El Poder en Movimiento: Los Movimientos Sociales, la Acción Colectiva y la Política”, ya deja ver como tesis central de su obra que:

[...] la gente participa en acciones colectivas como respuesta a un cambio en la pauta de las oportunidades y restricciones políticas y, mediante el uso 
estratégico de la acción colectiva, genera nuevas oportunidades, que serán aprovechadas por otros en ciclos de protesta cada vez mayores. (Tarrow, 2012, p. 67-68).

El hilo argumentativo de este planteamiento es desarrollado dentro del contexto de los conflictos y las controversias que experimentan las democracias y otras formas de gobiernos, para hacer frente a las demandas de los ciudadanos. Tal propósito se hace desde la perspectiva de análisis de Jürgen Habermas (2004), concretamente a partir de sus tres modelos normativos de democracia: liberal, republicanos y deliberativo, dando así una respuesta a la discusión planteada en los Estados Unidos entre comunitaristas y liberales.

En estos tres modelos Habermas (2004) explica el papel que juegan los ciudadanos en el proceso de formación política a través de su relación con el Estado. El autor lo que hace es explicar cómo se comportan los ciudadanos en el proceso de formación de la voluntad y de la opinión pública de acuerdo con estos tres modelos normativos de democracia.

Con el propósito de aclarar en este artículo, la importancia del movimiento social para la ciencia política, se toman como ejemplos estos tres modelos normativos de democracia planteados por Habermas, y se va más allá, al resaltar el rol que juega el movimiento social en el proceso de formación de opinión pública para lograr cambios que permitan la inclusión de los excluidos. Es una nueva forma de entender el comportamiento colectivo, en el que la participación, a través del movimiento social, dé lugar a que los sectores menos integrados o que se le niegue la integración a la sociedad puedan hacerlo a través de la fuerza que genera el movimiento social para impulsar el cambio.

Señala Habermas (2004) que el proceso de formación democrática en la concepción liberal, desempeña la tarea de programar al Estado en interés de la sociedad. En este modelo el Estado es concebido "[...] como el aparato de la administración pública y la sociedad como el sistema de interrelación entre las personas privadas y su trabajo social estructurado en términos de la economía de mercado” (Habermas, 2004, p. 231).

Aquí la política, vista en el sentido de la formación de la voluntad política de los ciudadanos, tendría la función de “[... ]amarrar e impulsar los intereses sociales privados frente a un aparato estatal especializado en el empleo administrativo del poder político para alcanzar fines colectivos" (Habermas, 2004, p. 231). 
El status de los ciudadanos está determinado por la medida de los derechos subjetivos que tienen frente al Estado y frente a los demás ciudadanos, “[...] disfrutan de la protección del Estado mientras persigan sus intereses privados dentro de los límites trazados por leyes y esto incluye también la protección frente a las actuaciones estatales que vayan más allá de las reservas legales de intervención” (Habermas, 2004, p. 232-233).

Los ciudadanos controlan que el poder del Estado se ejerza en relación con sus intereses; la formación democrática de la voluntad se lleva a cabo en la forma de compromisos entre intereses, que se configuran dentro de una constitución que disciplina el poder estatal mediante las normas establecidas.

En la concepción republicana, "La política no se agotaría en dicha función de mediación, sino que representaría más bien un factor constitutivo del proceso de socialización en su conjunto” (Habermas, 2004. p. 231), es decir, la política es vista como una forma de configurar la voluntad de acuerdo con un conocimiento recíproco entre los ciudadanos, que actúan solidariamente en el proceso de integración social.

En esta concepción el status de los ciudadanos no se determina por el modelo de las libertades negativas, sino por las libertades positivas, es decir, los ciudadanos, a través de la participación, pueden llegar a ser lo que ellos mismos desean, el proceso político no es visto como una bisagra entre el Estado y la sociedad. El Estado cumple el papel de salvaguardar el proceso inclusivo de formación de la opinión y voluntad común. Se garantiza la integridad de la vida en común autonomía e igualdad de derechos y basada en el respeto recíproco. Para los republicanos el derecho es la determinación de la voluntad política predominante, la formación de la opinión y de la voluntad política, obedece a una comunicación pública orientada al entendimiento, el diálogo se convierte en el instrumento de la política.

La concepción deliberativa,

[...] hace referencia a una cierta actitud propicia a la cooperación social, a saber, a esa disposición abierta a ser persuadido mediante razones relativas a las demandas de los otros tanto como a las propias. El medio deliberativo es un medio bienintencionado para el intercambio de puntos de vista -incluyendo los dictámenes de los participantes acerca de su manera de comprender sus respectivos intereses vitales“[...] en el que un voto, sea cual sea, representa un conjunto de juicios” (Habermas, 2004, p. 237). 
Este modelo se apoya en las condiciones comunicativas bajo las cuales el proceso político tiene para sí la presunción de producir resultados racionales porque se lleva a cabo en toda su extensión de un modo deliberativo.

Habermas (2004) deja claro que en los tres modelos el proceso de la formación de la voluntad democrática tiene funciones distintas; en la concepción liberal, su función es legitimar el ejercicio del poder político; en la concepción republicana, su función es esencialmente más fuerte, de construir la sociedad como una comunidad política y de mantener vivo en cada elección el recuerdo de ese acto fundacional; en la concepción deliberativa, el sistema político no es ni el centro ni la cúspide, ni tan siquiera el modelo de la sociedad que acuñará las estructuras de esta, sino tan solo un sistema de acción entre otros. Es decir, el proceso de la formación de la voluntad política va más allá de los procesos formales e informales de institucionalización de la voluntad y de la opinión pública, más bien guarda una interna conexión con los contextos de un mundo de la vida, diferente con dicho tipo de política, y por su parte también racionalizado. En este modelo el proceso político de formación de la voluntad, como se ha indicado, tiene la presunción de producir resultados racionales porque se lleva a cabo en toda la extensión de un modelo deliberativo.

Al tener claro el modelo de Habermas (2004), se puede establecer el papel que juegan los movimientos sociales en esa relación del Estado y el individuo en el proceso de la formación de la voluntad política, para generar cambios que produzcan la inclusión de los ciudadanos que no se encuentran representados dentro del contrato social.

En el modelo liberal el individuo actúa cuando sus intereses están amenazados; en el republicano el ciudadano por ética debe intervenir en la acción del Estado cuando este va en contra del bien común; en el deliberativo el Estado debe crear los mecanismos necesarios para que se fomente el debate y las decisiones sean tomadas por consenso.

El movimiento social puede ir mucho más allá del modelo deliberativo propuesto por Habermas, porque no solo logra que las decisiones se hagan por consenso, sino que impulsa cambios aún con la resistencia del Estado, al unir fuerzas para enfrentarse a élites, autoridades y antagonistas sociales, y, así, lograr los cambios que ninguna otra institución de acción colectiva puede. Sus desafíos colectivos en el proceso de interacción alcanzan la solidaridad, atrayendo la atención de sus oponentes y de terceras personas. Su capacidad de convocatoria desafía a los egoísmos personales, la desorganización y la represión del Estado. 
Esta capacidad de desafío los diferencia de cualquier otro tipo de acción colectiva, pues el movimiento social no son acciones individuales ejercidas colectivamente (grupos), sino individuos ejerciendo acciones colectivas (Movimiento Social), que incluso logran el apoyo de actores que no están vinculados directamente con los intereses del movimiento, es el caso de personas que apoyan a los movimientos LGBT sin pertenecer a ellos, o de los movimientos sociales que tienen como objetivo alcanzar o frenar cambios políticos y logran el apoyo de todos los sectores aun con diferencias ideológicas y partidistas, como por ejemplo el apoyo alcanzado por el movimiento estudiantil venezolano para frenar el intento de reforma constitucional del 2007 que quiso llevar a cabo Hugo Chávez en Venezuela, para imponer su modelo político, que dio lugar al triunfo del No en ese referéndum.

Se puede asegurar que si esa acción hubiese sido liderada solamente por la clase política opositora venezolana no hubiera alcanzado el éxito que si logró el movimiento social liderado por los estudiantes venezolanos, pues la sociedad política venezolana estaba muy dividida; de allí que si los políticos de oposición lideraban ese proceso, la pugna que se venía dando entre los dos sectores, los afectos al gobierno y la oposición, no les permitía permitido coincidir. El movimiento estudiantil le inyectó una fuerza moral a la convocatoria, de no apoyar la propuesta de reforma, porque abordó la discusión como un movimiento de la sociedad civil que luchaba contra la implementación de normas que atentarían contra el derecho de todos los venezolanos y le quitó impronta partidista.

Ahora bien, sería imposible el análisis y compresión adecuada de fenómenos en los que estén presentes todos los rasgos anotados, sin la adopción de un concepto de movimiento social que permita diferenciarlo de los movimientos políticos u otros movimientos que no son considerados como tal, pues las diferentes definiciones y teorías de movimientos sociales no permiten tener una precisión diáfana del fenómeno para así poder distinguirlos de otros fenómenos colectivos y avanzar en la interpretación de un campo que se considera fundamental para entender los cambios que se están produciendo en la sociedad actual, además de su alcance para lograrlos ante la crisis de liderazgo y de los partidos políticos que se vive actualmente.

La definición de movimiento social expuesta aquí impide asumir como movimiento social el movimiento a favor del aborto o el movimiento a favor de la pena de muerte, a estos se les concibe como movimientos de opinión pública. Se entiende a los movimientos sociales como una lucha por las 
conquistas, progresividad y no negación de derechos, donde su valor radica en el componente cognitivo de la discusión, es decir que estos nunca pueden ir en contra de los derechos, de su progresividad y, mucho menos en contra del fortalecimiento de la democracia, por tal razón estos movimientos pueden ser concebidos como movimientos de controversia pública y no movimientos sociales, porque si bien están presente los términos "en defensa de la vida" y "a favor de una elección”, nunca se puede ir en contra de un principio tan fundamental como la vida de otra persona, aunque se tenga la capacidad de elegir. El movimiento social lucha por derechos universales, mientras que el movimiento político antepone intereses.

Por estas razones es que no se puede entender cualquier acción colectiva como movimiento social, en este la acción colectiva es producto y objeto de una acción consciente, orientada por los elementos cognitivos que permiten conocer y digerir las propuestas que dan significado al cambio que buscan, por tal motivo la acción tiene sentido tanto para los que participan en sus actividades (y eventualmente obtendría un beneficio directo de los cambios si estos son alcanzados), como de aquellos que lo apoyan de forma solidaria y de los que llegan a conocerlos a través de los diversos procesos de comunicación.

De allí que la cantidad de "movilizaciones sociales" no pueden ser entendidas todas como movimientos sociales; es necesario la definición de un concepto que permita aclarar. La concepción genérica e indiferenciada de que toda acción colectiva es un movimiento social, además de ser errada, haría innecesario su estudio, en el marco de la especificidad que ello demanda y, peor aún, impediría a la ciencia política el estudio adecuado de estos fenómenos sociales de interés politológico. Al contrario, los movimientos sociales, además de ser acciones colectivas dotadas de especificidad, que son fundamentales como comportamientos colectivos logrando imponer cambios en la sociedad, reclaman un estudio diferenciado de otras acciones colectivas, el cual debe iniciar por una definición precisa que identifique, discrimine y analice cada uno de los elementos que forman parte de su concepto

11 Se entiende por movilizaciones sociales, todo el conjunto de acciones colectivas que se dan en una sociedad, tales como: protestas, revueltas, manifestaciones públicas, marchas, movimientos políticos y movimientos sociales. Las diferencias de todas ellas con el movimiento social, es que tienen un carácter efímero, buscan reivindicaciones de demandas inmediatas, por esos son efímeras. En el movimiento social la lucha es incremental, más permanente, porque luchan por cambios sociales que demandan la transformación de la realidad social y muchas veces política. 
Precisamente, en este punto es donde se pone el énfasis de una necesaria revisión, en la cual quede muy clara la diferencia entre una acción colectiva basada en la rutina y lo normal, y otras orientadas a construir nuevos conceptos de interpretación y de organización social para la convivencia. Por ejemplo, los movimientos estudiantiles, ecológicos, LGBT, feministas, entre otros, son movimientos consagrados, pero las acciones llevadas a cabo por estos movimientos no necesariamente siempre llegan a convertirse en movimientos sociales, porque estos movimientos también realizan acciones de protestas con carácter reivindicativos y sólo se convierten en movimientos sociales cuando ejercen acciones para alcanzar nuevos contenidos y valores que desafían a los ya establecidos, dando lugar a la discusión de si merecen o no esos derechos, es aquí donde está la esencia del movimiento social.

De hecho, son las demandas explicativas planteadas por este tipo de acciones las que han rebasado las posibilidades de las diversas definiciones que en la actualidad se han dado de movimientos sociales, dejando en evidencia su bajo rendimiento teórico y lógicamente han hecho necesario una definición, que por la vía de una integración racional de la multiplicidad de definiciones existentes, permita diferenciarlos de otras acciones colectivas como: tendencias sociales, movimientos de opinión pública, movimientos políticos, protestas o de cualquier otra acción colectiva rutinaria, e ir más allá de las generalizaciones empíricas.

\section{El movimiento social y su importancia para la participación}

En esta parte se argumenta el porqué de la significación de diferenciar lo que se entiende en este artículo por movimiento social y por movimiento político, a diferencia de otros autores que llegan a definir al movimiento político como movimiento social, cosa que al entender son procesos muy distintos; y, los argumentos que se exponen aquí analizan el movimiento político $15 \mathrm{M}$ sucedido en España, que algunos lo denominan movimiento social, como por ejemplo Díez García y Laraña en su libro: "Democracia, Dignidad y Movimientos Sociales: El surgimiento de la Cultura Cívica y la Irrupción de los 'Indignados’ en la Vida Pública” (2017); así como el movimiento social de los estudiantes del 2007 en Venezuela que buscaba frenar un cambio político. 
Lo primero que se pude decir es que en el movimiento político los problemas se plantean en términos políticos de demandas no cumplidas, de desavenencias e inconformidades, de justicias e injusticias, tal como lo plantea García Pelayo (2009) en su Idea de la Política, cuando señala que: “[...] la política se despliega en la tensión, el conflicto y la lucha [...]” y, esta imagen de la política desarrollada por el autor en el mismo libro se "centra en torno a la tensión y a la lucha, de modo que la política tiende a estar presidida por el momento polémico" (García Pelayo, 2009, p. 1765), es decir que, en principio, la idea de la política de para él:

[...] centrada en torno al poder y a la lucha es propia de épocas críticas en las que se pretende poner al desnudo o desenmascarar las apariencias de las cosas, pero una vez puesta las cosas en claro, puede servir tanto a una tendencia conservadora como a una tendencia revolucionaria[...] (García Pelayo, 2009, Vol.2. p. 1768).

En el movimiento social no existe esta dicotomía, porque las manifestaciones no se dan debido a las afirmaciones de una colectividad que aspiran participar en el poder 0 influir en su distribución, por el contrario, en el movimiento social las manifestaciones se dan en razón de la identidad colectiva ${ }^{12}$ que logra el grupo que lucha por derechos que le son negados, cuando sus intereses y puntos de vistas que no tienen una relación con los objetivos e intereses de los otros ciudadanos que no forman parte del movimiento, son asumidos por estos precisamente por el reconocimiento que tienen de los otros de luchar por sus derechos; distinto en el movimiento político que se mantienen posiciones $\mathrm{y}$ visiones ideológicas.

El movimiento social pierde esta fuerza y puede desaparecer y no alcanzar sus objetivos, cuando la lucha por sus aspiraciones caen en el terreno ideológico o bajo perspectivas marxistas revolucionarias o de cualquier otra tendencia política que le hacen perder su impulso porque se partidiza e ideologiza la discusión, cosa que no puede pasar, porque la lucha del movimiento social no es una pugna por el ejercicio del poder, sino una lucha que busca el mayor consenso para influenciar en el ejercicio del poder y alcanzar los cambios

\footnotetext{
12 Identidad colectiva, es una determinada forma de ver y situarse en las carencias y conflictos de la realidad, es algo que se comparte con los demás y que influye más o menos en la vida de quienes comparten algo. Es una forma de definir la realidad junto con otros individuos, algo que nos une, algo que forma parte de nuestras vidas que compartimos, es un referente para interpretar la realidad. La identidad colectiva da sentido a lo que creemos, y a lo que hacemos. (Cfr. Pedro Ibarra, 2005, pp. 169-170).
} 
que se propone. Al respecto, es necesario aclarar que si bien se propone en este artículo diferenciar al movimiento social del movimiento político, esto no impide concebirlos como una nueva forma de participación política no institucionalizada en organizaciones políticas, porque se les considera, en términos de García Pelayo (2009), fenómenos políticamente condicionantes ${ }^{13}$, es decir que no siendo políticos en sí mismo tendrán efectos decisivos, ya que la forma como se desenvuelven logran un consenso que obligan al sistema a tomar decisiones con respecto a las demandas planteadas.

Al analizar el concepto dado por el profesor Salamanca (2011), se aprecia que este también lo entiende como fenómeno políticamente condicionante, cuando señala que:

[...] los movimientos sociales no son siempre fenómenos organizados; pueden encontrarse bajo la forma de sentimientos de rechazo, de agitación colectiva, de aspiraciones al cambio de ciertas situaciones o instituciones que no consiguen el vehículo adecuado para expresarse y, por tanto, tienen en la protesta, en la rebelión y en otras formas de acción colectiva, la vía para hacerlo (Salamanca, 2011, p. 54).

En definitiva, su conceptualización permite afirmar que estos fenómenos pueden ser entendidos como una nueva forma de participación política no institucionalizada para alcanzar cambios en una sociedad, al expresar son:

[...] un tipo de acción permanente, relativamente coordinada, con grado de concertación diversa -tanto espontánea como organizada- con cierto nivel de organización, para provocar cambios sociales y/o políticos en una

13 "Fenómenos políticamente condicionantes, o sea, aquellos fenómenos que, no siendo políticos en sí mismo, pueden tener efectos a veces decisivos sobre la política. Así, por ejemplo: ni la elevación de la duda a principio metódico por Descartes, ni la filosofía natural de Newton, ni la teoría dialéctica hegeliana son, en sí mismos, fenómenos políticos, sino doctrinas de carácter gnoseológico y ontológico, cuya intención es teórica y no práctica. Y, sin embargo, se convirtieron en políticamente operantes, cuando los filósofos del siglo XVIII trasladaron la duda metódica al campo de las instituciones políticas existentes sometiéndolas a una crítica de las que dedujeron su falta de derecho a la existencia y, por tanto, la necesidad de su reemplazo por otras instituciones más coherente con los principios de la razón: cuando Montesquieu aplicó los principios de la filosofía de Newton al el estudio de la realidad política y llegó -entre otras cosas- a su teoría del equilibrio de poderes, de tan decisiva influencia para la estructuración racional del Estado Liberal; o cuando Marx trasladó la dialéctica a las tensiones sociales, dando así carga política a lo que en Hegel permanecía en el plano de la lógica. Todos estos casos nos ponen de manifiesto el condicionamiento de la política por fenómenos que, en sí mismo, carecen de entidad y de intencionalidad política, pero en cuanto que ellos han hecho posible que la política sea tal cual es, ellos mismos han pasado a formar parte del ámbito que interesa a la teoría política". (García Pelayo, 2009, p. 1790) 
sociedad 0 en sectores de ella que pueden hacer uso de la protesta 0 de otros medios para el logro de sus objetivos. (Salamanca, 2011, p. 54).

Por tal razón, cuando se leen los planteamientos hechos por los autores Díez García y Laraña (2017) para referirse al movimiento 15M y considerarlo un movimiento social, en su libro antes citado, donde dicen que:

La difusión del 15M fue potenciada por la de sus definiciones colectivas de importantes problemas económicos y políticos que afectan a muchos ciudadanos y a los jóvenes en especial, que son percibidos como los abanderados e impulsores de tales definiciones. Problemas como la precariedad y falta de expectativas que afectaban a una parte importante de los seguidores y simpatizantes de este movimiento (y pasado los años sigue afectando a muchos jóvenes y ciudadanos), cuya base social estaba integrada principalmente por jóvenes, pero se amplió a lo largo del tiempo (Díez García y Laraña. 2017, p. 227).

Se puede afirmar que tal manifestación no es un movimiento social sino un movimiento político, donde se presenta una discusión de demandas de políticas públicas que son objetos de controversia política en la sociedad española.

Son muchos los argumentos que se encuentran en la lectura de este libro que dan sustento -a la interpretación- del $15 \mathrm{M}^{14}$ como un movimiento político y no social, por ejemplo cuando señalan:

“Sin embargo, este movimiento fue identificado como 'izquierdistas' por algunos políticos y desde los mass media. En la academia, asimismo algunos autores incidieron en el argumento de que se trataba de un movimiento

14 El 15M fue la irrupción de los indignados en la vida pública española que adquirió gran visibilidad y repercusión mediática a raíz de las campañas que fueron sucediéndose en numerosas plazas públicas de las principales ciudades del país, desde que un pequeño grupo de cuarenta personas decidiera permanecer en la Puerta del Sol tras las manifestaciones celebradas en la tarde del 15 de mayo de 2011 en Madrid. Esta manifestación fue convocada por la plataforma Democracia Real Ya (DRY) y tuvo lugar junta a otras que esa misma tarde concurrieron de forma más análoga en más de cincuenta ciudades del país. Los allí presentes corearon lemas como «Lo llaman democracia y no lo es», "Que no, que no, que nos representan» o «El pueblo unido jamás será vencido». Además de los problemas económicos que acuciaban a los ciudadanos, la precariedad, el desempleo, los problemas de vivienda, y de las medidas de austeridad y recortes en los servicios públicos, los activistas hicieron una intensa crítica de los partidos políticos, fuertemente vinculada a la responsabilidad que le atribuyen por la situación económica y social del país. (Díez García y Laraña, 2017. p. 213-222 y 226). 
cuyos activistas y participantes se posicionaban a la izquierda (Calvo et al., Likki, 2012, entre otros), una cuestión que abordo en el siguiente capítulo desde una perspectiva cuantitativa” (Díez García y Laraña, 2017, p. 258).

Aunque los autores tratan de desmontar estos argumentos para identificar al movimiento $15 \mathrm{M}$ como un movimiento social, el que sin duda ha podido convertirse si no se hubiese partidizado e ideologizado, no lo logran, pues al ser pasadas ciertas particularidades de este movimiento por el tamiz de los elementos que se han identificado como conformadores del concepto de movimiento social, dichas particularidades impiden tal calificación al defraudar las expectativas teóricas integradas en el plano ideal de la construcción racional elaborada de dicho concepto.

Expresado en términos más concretos, no se puede calificar de movimiento social al movimiento $15 \mathrm{M}$, debido a que este movimiento no permite esa relación propia del movimiento social que es esa relación inseparable e interactiva entre sus reivindicaciones y las características relacionadas con la identidad individual y colectiva. Y no lo logra porque esa valoración social favorable que lo caracteriza, fundamental para reforzar sus acciones, se pierde cuando el movimiento está partidizado e ideologizado, y para nadie es un secreto la influencia y participación que tuvieron en el 15M, personas que idearon e impulsaron la creación del partido PODEMOS. Es tanto así que los autores arriba citados señalan:

"La formación política podemos y las iniciativas de confluencias cosecharon importantes éxitos en las elecciones europeas de 2014, municipales de mayo de 2015 y generales de diciembre de 2015 y junio de 2016 (en esta última, Podemos en alianza con IU). Cuatro grandes citas electorales en el que el incremento de la popularidad de voto y la caída del bipartidismo han sido muy significativos, aspectos ambos -pluralismo y crítica al bipartidismoque los indignados pusieron en la agenda de la vida pública española con su irrupción en 2011 y su alto potencial de definición y persuasión colectiva” (Díez García y Laraña, 2017, p. 353).

Sin duda, nadie puede desconocer la gran movilización social que logró el movimiento político surgido el 15 de mayo de 2011 en Madrid, así como, también que esa fuerza se desvaneció, y es esta, precisamente, una de las diferencias del movimiento político con el movimiento social, este último es incremental en sus fuerzas para lograr el objetivo y lo puede alcanzar porque no se partidiza. Es posible que un movimiento social no logre sus objetivos y 
sufra un proceso de enfriamiento, pero puede retomar ese impulso inicial en cualquier momento, mas no cuando se ha partidizado e ideologizado, estos dos elementos lo truncan. Estas son las razones por las cuales, de acuerdo con el concepto de movimiento social formulado en este artículo, el M15 no se convirtió en un movimiento social como sí lo pudo hacer el movimiento estudiantil el 2007 en Venezuela.

La acción social en el movimiento político al momento de su surgimiento puede dar lugar a una gran movilización e impulsar algún cambio, pero en su desarrollo cuando se comienzan a decantar sus propuestas puede perder su impulso, pues su apoyo va a depender de la visión ideológica, partidista, social y doctrinaria que se tenga del asunto. El movimiento social, muy por el contrario, maneja su estrategia alrededor de figura de derecho y no de beneficio y competencia, este busca presionar y persuadir el sistema político para lograr el cambio, el movimiento político busca llegar al poder para implementar el cambio propuesto.

Ahora bien, es muy distinto el movimiento social que busca impulsar o detener un cambio político, es el caso del movimiento social estudiantil vivido en Venezuela el 2007. Desde la llegada de Hugo Chávez al poder en 1998, la sociedad venezolana ha estado muy movilizada, politizada y partidizada, dándose una gran división dentro de la misma; ha sido difícil lograr políticas consensuadas en estos tiempos, y, lo que ha predominado es la imposición de un modelo político: el socialismo del siglo XXI a la sociedad venezolana por parte de los que gobiernan, aun con gran rechazo por un vasto número de la población como se ha podido observar en las grandes manifestaciones vividas en las calles venezolanas estos últimos tiempos.

En el 2007 la sociedad venezolana vivió una experiencia fundamental para la vida de la república, por lo que es primordial resaltar el alcance de los movimientos sociales, y de allí el empeño por tener claro la significación del concepto. Hasta ese momento no había sido posible lograr un consenso en la sociedad venezolana que pudiera hacerle frente al poder arrollador que imponía Chávez a través del control absoluto de las instituciones del Estado.

A partir de abril del 2006 el movimiento estudiantil venezolano, el cual estaba aletargado, despertó y se incorporó a la lucha de la vida nacional a raíz de la muerte de los hermanos Faddoul Diab ${ }^{15}$. Y continuarían con mucha más

15 Los cuerpos de los hermanos Bryan, Kevin y Jasón Faddoul Diab, de 12, 14 y 17 años, respectivamente, hijos de un empresario canadiense de origen libanés, fueron localizados el 4 de abril en una zona 
fuerza a partir del mayo del 2007, después de que el 27 de ese mes cesara la trasmisión de Radio Caracas Televisión al renovarle la concesión el gobierno.

Desde ese momento el movimiento estudiantil comenzó una serie de manifestaciones sociales donde sus consignas estaban orientadas a la lucha específica por el respeto del derecho a libertad de expresión en Venezuela, y en su desarrollo avanzó hacia una lucha en general por la defensa de los derechos civiles y políticos.

Este movimiento social llevado a cabo por los estudiantes logró unir una amplia variedad de simpatizantes, tarea que le era difícil llevar a cabo a los partidos políticos que se oponían en ese momento a las políticas llevadas a cabo por Hugo Chávez, lo cual permitió darle un carácter duradero al movimiento que cada día fue cogiendo más fuerza y le dio también un gran significado político como agente de cambio social.

Toda esta fuerza acumulada que fue obteniendo este movimiento estudiantil le permitió, junto al país que se levantó a luchar por frenar este cambio, oponerse con éxito a la reforma constitucional propuesta el 15 de agosto, por el presidente Hugo Chávez, a la Asamblea Nacional, donde presentó un proyecto para modificar a la Carta Magna de 1999, una reforma de la Constitución que él mismo impulsó y que calificó como "la mejor del mundo”, y cuya materialización le hubiere permitido la reelección indefinida -que después impuso por la vía de la enmienda constitucional-, la creación de nuevas instancias de Gobierno, una nueva organización administrativa del país y la modificación del sistema socioeconómico, para impulsar el "Socialismo del Siglo XXI"16. Este comportamiento adoptado por la sociedad venezolana encaja dentro del concepto de movimiento social plateado por Turner y Killian (1987), quienes dicen que: "Un movimiento social puede definirse como 'una colectividad que actúa con cierta continuidad para promover o resistir un cambio en la sociedad (o grupo) de la que forma parte”. (Turner y Killian, 1987, p. 223).

boscosa del estado Miranda-Venezuela junto al de Miguel Rivas, de 30 años, chófer de la familia. Los cuatro habían sido secuestrados el 23 de febrero por supuestos agentes policiales. El crimen consternó el país. (Según información de los Diarios El Universal y El Nacional de Venezuela, versión digital)

16 El Socialismo del Siglo XXI, fue la propuesta del modelo político presentado al país en septiembre del 2007, por el presidente Hugo Chávez Frías, en su denominadas Líneas Generales del Plan de Desarrollo Económico y Social de la Nación 2007-2013, y cuyas directrices eran la Nueva Ética Socialista, La Suprema Felicidad Social, Democracia Protagónica y Revolucionaria, Modelo Productivo Socialista, Nueva Geopolítica Nacional, Venezuela: Potencia Energética Mundial y Nueva Geopolítica Internacional. Para más información ver (Contreras, 2011, p. 170-182). 
Esta propuesta fue el desencadenante que posibilitó que con el movimiento estudiantil venezolano confluyeran sectores que aunque apoyaban a Chávez, no apoyaban su reforma, dando lugar a que los venezolanos en el referéndum del 2 de diciembre del 2007, por un estrechísimo margen, 50,7\% frente a 49,2\%, según cifras del CNE, le hayan infligido su primera derrota en las urnas en sus nueve años de Gobierno, rechazando así la reforma que le hubiera dado un poder casi ilimitado.

Se puede afirmar que, por las razones ya expuestas en este artículo, si en Venezuela no se hubiere articulado ese movimiento social, hubiera sido imposible frenar la reforma constitucional. Este hecho resalta la consideración de tener claro qué es un movimiento social y su diferencia con otras formas de acción colectiva, y su rol para imponer o frenar cambios que afecten la vida de los ciudadanos, al lograr objetivos que al movimiento político se le hace difícil alcanzar. Se ha de resaltar que esta misma fuerza se hizo presente en el primer movimiento opositor que tuvo Hugo Chávez Frías a partir de octubre de 2000 y hasta mediado del 2001 con el lema de “Con mis hijos no te metas”, después del anuncio del Decreto Presidencial 1011, cuyo texto modificaba parcialmente el Reglamento del Ejercicio de la Profesión Docente, al crearse una nueva figura administrativa, la de los supervisores itinerantes, que buscaba la ideologización de la educación y adoctrinamiento de los estudiantes, y que gracias a esta lucha y al apoyo que tuvo por parte de la sociedad venezolana no pudo concretarse.

En Venezuela en estos últimos 20 años el chavismo ha estado confundiendo sus grupos políticos con movimiento sociales, era muy común escuchar a Chávez, (y ahora a Maduro), hablar de los movimientos sociales que apoyan a la revolución como una forma de darle legitimidad a la misma. Tanto ha sido el abuso e incomprensión del término que muchas leyes promulgadas por el chavismo como por ejemplo la Ley Orgánica de los Consejo Comunales -(Ley inconstitucional pero que no es el tema que nos ocupa aquí)-, establece en su artículo 2 que los movimientos sociales, son instancias de participación, para construir el nuevo modelo de sociedad socialista de igualdad, equidad y justicia social.

Hacen un mal uso del concepto, confundiéndolo con movimientos políticos, desconociendo que la relación de los movimientos sociales con el Estado y el gobierno siempre serán de conflictividad, ya que es la estrategia que utiliza para impulsar los cambios propuestos, pues el movimiento social en el proceso activo de construcción de identidades colectivas como forma de ganar adeptos al mismo, entra en un proceso de competición con el contramovimiento en 
un intento de persuadir tanto a las autoridades como a sus simpatizantes con que su causa es justa, es de esta manera como él trata de persuadir o influir en el sistema político para imponer y lograr los cambios, mientras que el movimiento político además de los cambios que se propone, busca alcanzar el poder para producir los cambios, y en su lucha por lograr identidades colectivas sus acciones se partidizan e ideologizan.

El movimiento social busca crear marcos interpretativos que generen la mayor cantidad de apoyo, el movimiento político que algunos llaman movimiento social lo que busca es desestabilizar al gobierno a través de manifestaciones, protestas que en la mayoría de los casos llegan al uso de la violencia, es el caso de las diversas manifestaciones que vivieron países como Ecuador, Chile y Colombia, a finales del 2019, que fueron llamados por algunos movimientos sociales, pero que a pesar de contar con grandes manifestaciones de apoyo no pueden calificarse como tales, porque una de sus características es que su apoyo es incremental, no se politiza, lo que le permite tomar más fuerza e impulsar sus cambios. Mientras que en el movimiento político la acción colectiva se diluye por no haber consenso en las propuestas, por los actos violentos que se cometen y que dan lugar a que se pierda su fuerza inicial, tal como ha sucedido en estos países.

\section{Consideraciones finales}

Dicho en breve, la idea de este artículo es ofrecer una clarificación del concepto para ayudar a una mejor comprensión del fenómeno de los movimientos sociales y avanzar con esta categoría de análisis en el tema de la participación política, en estos tiempos donde existe una crisis de liderazgo y de los partidos políticos.

Se destaca la importancia de su definición por el destacado rol que se la asigna dentro de una teoría de la democracia, para así evaluar y enfrentar los retos de participación que tienen los ciudadanos de hoy para luchar por su inclusión. Por tal motivo se resalta el interés de no confundir el concepto de movimiento social con cualquier otro tipo de acción colectiva y específicamente con los movimientos políticos. Este tipo de confusión es generada por actores políticos interesados en presentar al movimiento político como movimiento social, con el objetivo de darle indebidamente la fuerza moral y social que lo caracteriza y que lo convierte en el motor de cambio; ello sin descartar que, en ocasiones, a ese objetivo esté asociada una justificada ignorancia acerca el tema. 
La continuidad de una práctica política y también politológica en la que se siga entendiendo e identificando de forma indiscriminada a la acción colectiva como movimiento social, conducirá a una consolidación en la banalización de la problemática que supone su adecuada interpretación, y de esta manera se trunca el camino a una categoría de análisis que puede ser entendida como una nueva forma de participación política no institucionalizada políticamente que permita alcanzar cambios sin llegar a partidizarse, lo que le da una gran fuerza de convocatoria para que confluyan en él, tanto a los que buscan el cambio como a los que no, pero que reconocen la lucha como legítima y permite alcanzar el consenso para impulsarlo.

Además, no hay que perder de vista que el movimiento político es producto de una coyuntura, mientras que el movimiento social tiene una existencia previa en la sociedad, no se limita única y exclusivamente a un nivel visible, aunque es relevante; su existencia es previa de manera subterránea en las bases del orden social, y cuando se manifiesta públicamente es porque ya existía, no sucede esto con el movimiento político donde la acciones que impulsan su aparición son evidentes y fácilmente compartidas por los ciudadanos, mientras que el movimiento social requiere de la construcción de significados, es un proceso incremental.

El movimiento social es espontáneo, el único recurso con que cuentan para imponerse es la opinión pública, por lo que dependen del mayor número de participantes y grupos que lo apoyen en sus manifestaciones, por esta razón no pueden partidizarse o etiquetarse ideológicamente, por ello sus argumentos e interpretaciones deben estar enmarcados en los temas que tratan, es este comportamiento lo que determina el éxito de los movimientos sociales y a la vez lo diferencia de los movimientos políticos o cualquier otra manifestación de acción colectiva.

Todas las razones expuestas aquí, producto de las reflexiones surgidas en la cátedra de Historia de las Ideas y Movimientos Sociales Contemporáneos en la Escuela de Estudios Políticos y Administrativos de la Universidad Central de Venezuela, y que han sido aplicadas como parte del estudio del tema al análisis de los casos específicos de las manifestaciones sociales sucedidas en Venezuela en el 2007 y España en el 2015, es por lo que se hace necesario repensar el concepto.

Para contribuir a este debate se considera que un movimiento social debe entenderse como aquellos esfuerzos colectivos de movilizaciones que tienen 
por objeto provocar o impedir un cambio que afecte los intereses de los ciudadanos y que para su éxito requiere un proceso de racionalización que le permita la articulación de las preferencias para, de esta manera, lograr la identidad y posterior acción colectiva, por lo cual no puede partidizarse ni ideologizarse, pues de ello depende su éxito.

En resumen, el propósito de este artículo ha sido comprender el concepto de movimiento social, y dado que se comprende algo cuando se esclarece su significado, sin duda entonces que los movimientos sociales no pueden ser conocidos más que en el marco de su diferenciación de las otras acciones colectivas en las que están articulados, de allí la necesidad de un concepto claro, lo que contribuye a un mejor análisis y compresión de este fenómeno, dentro del campo de la ciencia política.

\section{Referencias}

Almeira Cáceres, G y Jerez, A. (2009), sociedad civil y nuevos movimientos sociales. Madrid: Cáritas Españoles. Editores.

Calderón, F. (1995), Movimientos sociales y política. La década de los Ochenta en Latinoamérica. Madrid: Siglo XXI editores, S.A de C.V.

Castells, M. (2000), movimientos sociales urbanos. Madrid: Siglo XXI de España Editores, S.A.

Contreras Hernández, J. G. (2011), El Estado Venezolano ante la globalización. Caracas: Facultad de Ciencias Jurídicas y Políticas. Universidad Central de Venezuela.

Contreras Hernández, J. G. (2012), Sociedad civil y ciudadanía. El reto de la Resistencia Democrática en Venezuela. Revista de la Facultad de Ciencias jurídicas y Políticas, Vol. 136, Págs.17-33. Caracas: Universidad Central de Venezuela.

Della Porta, D y Diani, M. (2011), Los movimientos sociales. Madrid: Editorial Complutense.

Díez García, R y Laraña E. (2017), Democracia, dignidad y movimientos sociales: el surgimiento de la cultura cívica de los 'Indignados' en la vida pública. Madrid: Centro de Investigaciones Sociológica.

García Pelayo, M. (2009), Obras completas. Vol. II. Madrid: Centro de Estudios Políticos y Constitucionales.

Farías, H. (1981), Algunas notas sobre el concepto de movimiento social. Revista de la Facultad de Ciencias Jurídicas y Políticas de la UCV, Vol. 61, Págs. 95-112. Caracas: Facultad de Ciencias Jurídicas y políticas de la Universidad central de Venezuela.

Funes Rivas, M. J y Adell Argilés, R. (2003), Movimientos sociales: cambio social y participación. Madrid: Universidad Nacional de Educación a Distancia.

Habermas, J. (1999), La Inclusión del Otro. Barcelona: Ediciones Paidós Ibérica.

Heberle, R y Gusfield, Joseph R. (1975), Movimientos sociales. Enciclopedia Internacional de las Ciencias Sociales, Vol. 7, Págs. 263-274. Madrid: Ediciones Aguilar.

Ibarra, P y Tejerina B. (1998), Los movimientos sociales. Transformaciones política y cambio cultural. Madrid: Editorial Trotta. 
Ibarra, P. (2005), Manual de sociedad civil y movimientos sociales. Madrid: Editorial Síntesis.

Javaloy, F, Rodríguez, A y Esteve E. (2001), Comportamiento colectivo y movimientos sociales. Madrid: Pearson Educación.

Koselleck, R. (2012), Historia de conceptos. Estudios sobre semántica y pragmática del lenguaje político y social. Madrid. Editorial Trotta.

Lachanel, C y Pirker, C. (2012), Movimientos sociales, derechos y nuevas ciudadanías en américa latina. Barcelona: Editorial Gedisa.

Laraña, E. (1999), La construcción de los movimientos sociales. Madrid: Alianza Editorial. Laraña, En y Josep. (2001), Los movimientos sociales. De la ideología a la identidad. Madrid: Centro de Investigación Sociológica.

McAdam, D., McCarthy, J.D y Mayer, Z. (1996), Movimientos sociales: perspectivas comparadas. Madrid: Ediciones Istmo.

Melucci, A. (1986), Las teorías de los movimientos sociales. Estudios políticos, 67, 6677. México, D.F.: Facultad de Ciencias Políticas y Sociales. Universidad Nacional Autónoma de México.

Offe, C. (1988), Partidos políticos y nuevos movimientos sociales. Madrid: Editorial Sistema.

Salamanca, L. (1998), Obreros, movimiento social y democracia en Venezuela. Caracas: Facultad de Ciencias jurídicas y Políticas. Universidad Central de Venezuela.

Salamanca, L. (2011), Protestas contra la tiranía: el nacimiento del movimiento ciudadano entre 1935 y 1937. Caracas: Universidad Central de Venezuela.

Scott Hunt, R. B y Snow, D. (2001), Marcos de acción colectiva y campos de identidad en la construcción social de los movimientos. Laraña, E y Gusfield, J., Los nuevos movimientos sociales. De la ideología a la identidad, 221-249. Madrid: Centro de Investigaciones Sociológica.

Sztompka, P. (1995), Sociología del cambio social. Madrid: Alianza Editorial.

Tarrow G, S. (2012), El poder en movimiento: los movimientos sociales, la acción colectiva y la política, Tercera Edición. Madrid Alianza Editorial.

Tejerina, B. (2010), La Sociedad imaginada. Movimientos sociales y cambio cultural en España. Madrid: Editorial Trotta.

Turner, R y Killian, L. (1987), Collective Behavior. New Jersey: Prentice-Hall, Englewood Cliffs.

Tilly, Ch. (2010), Los movimientos sociales, 1768-2008. Desde sus orígenes a facebook. Barcelona: Editorial Crítica.

Touraine, A. (1994), Crítica de la modernidad. México, D.F: Fondo de Cultura Económica, México.

Touraine, A. (2005), Un nuevo paradigma para comprender el mundo de hoy. Barcelona: Ediciones Paidós Ibérica.

Ullán De la Rosa, F. J. (2016), Teorías sociológica de los movimientos sociales. Madrid: Catarata.

Weber, M. (1984), La acción social: ensayos metodológicos. Barcelona: Ediciones Península. 